\title{
Coaching "change" while keeping the coach/player relationship strong
}

\author{
Federico Di Carlo (ITA)
}

ITF Coaching and Sport Science Review 2015; 66 (23): 9 - 10

\author{
ABSTRACT \\ Modern neuroscience is proposing time models on how changes in brain neuro-patterns \\ change human cognition, emotion and behaviour. Indeed the word "change" is very often \\ used by coaches at any grade and level to elicit different behaviours from athletes and \\ tennis players. However, in an individual sport like tennis in which self-esteem and \\ confidence are paramount, the word, concept and image of "change" may shake the \\ player's self-esteem and jeopardise the overall coach-player relationship.
}

\author{
Key words: coach, player, \\ change, performance \\ Received: 13 April 2015 \\ Accepted: 14 Juy 2015 \\ Corresponding author: \\ Federico Di Carlo \\ Email: info@theolivehill.com
}

\section{INTRODUCTION}

The neuro scientific approach is becoming more and more popular in sport coaching. Research has been conducted on the brain via MRI scans displaying results in neural plasticity and related cognitive, emotive and behavioural flexibility (Robertson, 1999). The fact is that the word "change" is becoming increasingly popular in cognitive, emotional and behavioural sport coaching (Lee, 2013). Coaches are aware that working with a tennis player means introducing news was of thinking and/or asking a player to use adapt to alternative coaching methodologies. A coach's presence on a court more often than not causes additional stresses on a player. However, coaching means introducing changes.

If coaches intuitively know that changes need to be proposed progressively and gradually, very often they miss the impact that "change" may have on the player mentality and how it may affect their relationship too. Change is indeed one of the hardest human tasks to undertake. Changing requires challenging the conceptual assumptions that a person holds for true and established. On the other side, it is widely accepted that trust and self-esteem are paramount to an athlete's best performance (Weinberg et al, 2011). Any coach requesting change must pass the athlete approval and his/her cognitive, emotive and behavioural system may oppose resistance (Dorfman, 2005). Challenging personal standing points, beliefs and concepts means exposure to unknowns, insecurities, doubt and fear; on the other side players need to rely on what he/ she knows, feels comfortable and secure with in order to perform and be competitive (Fox, 2010). So player resistance to change is normal and to be expected. So player resistance to change is normal and to be expected. Operating change without harming the player/ coach relationship is a paramount skill and a desire for all coaches.

Any time a coach is asking a player to make a change he is asking him to reduce his immune system (confidence and self-esteem) and making him more vulnerable (doubts and fear). It is not the case that most of athletes respond negatively to change However, not all athletes respond negatively, many are aware of the fact that by embracing change they are enabling their own development and therefore not undermining the coach's beliefs. Never ending improvement (trainability and the capacity to work on changes) is the trademark of a champion's mentality as much as a player's strong belief and perception about personal abilities and tennis skills. The risk is that by enhancing a trainable player's mentality the self-confident competitor may suffer. On the other hand by enhancing a self-confident competitor's mentality it may result in a player being reluctant to change

Unfortunately one potential outcome is the termination of a coach and player's relationship. The circuit is full of players that aren't improving with the turnover of coaches at an all-time high. Relationships between player and coaches often become conflictive (coaches blame players for not implementing the changes the coach believes are required and players blame coaches for not being capable of coach effectively).

\section{PRACTICAL APPLICATION}

So how should a coach approach these apparent contradictory aspects of a tennis player's mentality? How should a coach enhance the desire to change and the necessity to be confident in one player at the same time?

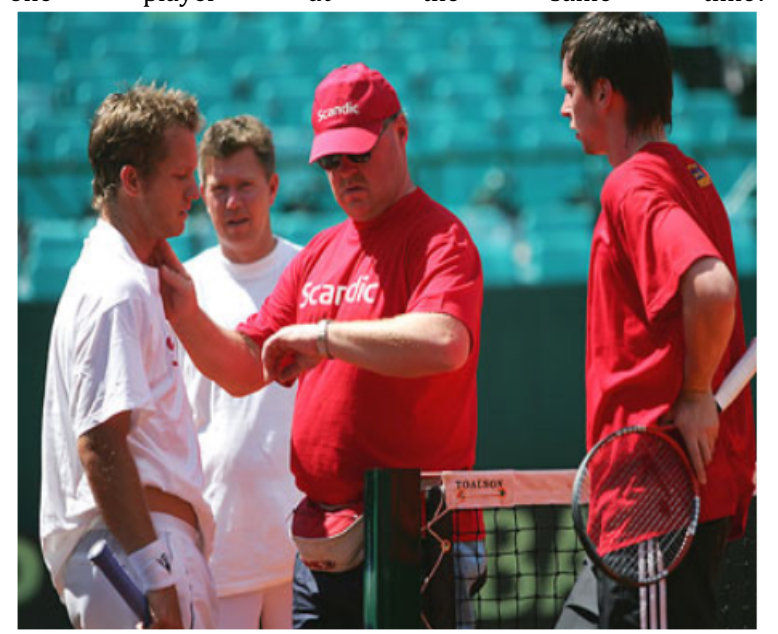

Consciousness.

In my opinion a coach should make clear to the player that a potential problem may exist and that if the process of changing is not clear, the end results of these coaching practices as well as the relationship between coach and player may be jeopardised. The player must be open, flexible and willing to accept and implement new/revised methods, skills, concepts while also maintaining their determination, confidence and trust in the new coaching practices when competing. The coach must be clear to the player that their relationship is based on trust and two-way open communication. 
Two steps forward one step back.

I believe a player must be informed that the process of change requires significant time, effort and stress. Introducing change means coming out of your comfort zone. It means challenging previous thoughts and beliefs may cause a player to endure a run of poor results in the short-term. Improvement as a result of change doesn't occur smoothly or at a steady rate. . Typically it results in a player showing initial signs of improvement before hitting a wall and perhaps faltering before finding their way again. Often the progression may seem as though the player is taking two steps forward and one step back. The process of improvement tends to take less time when a player has a positive mind-set and embraces the change. The coach must make clear that change is paramount enabling a player to achieve their potential and maximise their skill development

Make change friendly through communication.

Furthermore I think that a good communicative coach should avoid (ab) using the word "change" and "changing". He/she should make themselves clear so that when talking about "change" by no way is he/she criticizing the player's ability or mentality. Unfortunately, whenever using and hearing the word "change", our minds unconsciously build the image and the construct of error or mistake. Of course by telling a player that they must change something, it is implied that he/she is not doing something correctly and that they are doing it wrong. You may understand of course that the word "change" in that sense implies that a coach is criticising a player's actions or ability. It is a judgment on his perceived ability and skilfulness, an attack on his confidence and self-esteem. Moreover, the player may also feel that such criticism is not warranted and it is not consistent with his achievement history and career. For this reason, instead of the word/verb "change" I would highly recommend coaches replace it with "improve/improvement", "adjust/adjustment" or "upgrade". These statements imply that the player does not need to refuse and disregard his past acquisitions but that he may use it as a foundation on which to build from in the further and enable them to achieve higher levels of performance. These phrases also maintain a player's self-esteem and confidence.

You can bring a horse to water but you can't make him drink. In my opinion as a coach you can should take time to build a rapport with a tennis player; you can make communication processes straightforward; you can implement communication strategies to facilitate accepting changing on his side; you can schedule change activities in an easier to digest process; you can check and verify the process of changing. However, the action to undertake change

can only be taken from a player. Changing requires player effort and struggle and it is his/her choice to go for it or refuse it. There is not much you can do if the player himself is not willing to accept and undertake actions to change. In those cases, since improvement in the long term is impaired and your work is bound to produce poor or few positive results, it is up to you to decide whether it is worthwhile to continue working with that player.

\section{REFERENCES}

Brown, J. \& Fenske, M., (2010). The winner's brain, Da Capo Press. Di Carlo, F. (2012). Il cervello tennistico, \&MyBook.

Dorfman H.A., (2005). Coaching the mental game, The Rowman \& Littlefield Publishing Group Inc.

Fox, A., (2010). Winning the mental match, Morris Publishing, Kearney, NE, US.

Lee, I. (2013). Change: realizing your greatest potential, Best life media.

Patterson, K., \& Grenny, J., (2011). Change anything: the new science of personal success, Business Plus.

Robertson, I. (1999). Il cervello plastico, Rizzoli.

Weinberg, R.S. (1988). The Mental Advantage: Developing Your Psychological Skills In Tennis, Champaign, IL: Human Kinetics.

RECOMMENDED ITF TENNIS ACADEMY CONTENT (CLICK BELOW)

\section{ITF Academy}

Copyright (c) Federico Di Carlo 2015

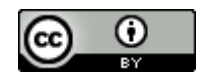

This text is under a Creative Commons BY 4.0

\section{license}

You are free to Share - copy and redistribute the material in any medium or format - and Adapt the content - remix, transform, and build upon the material for any purpose, even commercially under the following terms:

Attribution: You must give appropriate credit, provide a link to the license, and indicate if changes were made. You may do so in any reasonable manner, but not in any way that suggests the licensor endorses you or your use.

CC BY 4.0 license terms summary CC BY 4.0 license terms 